\title{
O ESPAÇO DA INTERDIÇÃO INTERDITADO PELA NOSTALGIA E PELO RISO \\ o Muro de Berlim e a "Alameda do Sol"
}

\author{
Élcio Loureiro Cornelsen \\ UFMG
}

\begin{abstract}
RES U M O
O objetivo deste artigo é discutir alguns aspectos teóricos sobre a categoria de espaço na literatura contemporânea. A análise do romance Am Kürzeren Ende der Sonnenallee (1999), do escritor alemão Thomas Brussig, demonstra que o autor constrói o espaço ficcional como miniatura, por meio da redução de um trecho de rua na antiga Berlim Oriental que assume a função de centro das ações romanescas.
\end{abstract}

\section{PALAVRAS-CHAVE}

Espaço ficcional. Romance de rua. Am Kürzeren Ende der Sonnenallee.

\section{O ESPAÇO E SUAS CONFIGURAÇÕES}

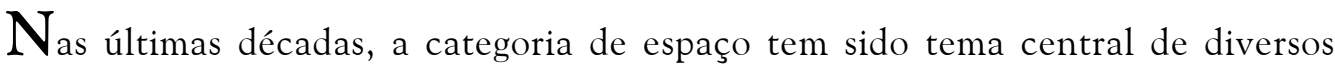
estudos no âmbito da literatura. Não obstante o modo diversificado com que é tratado, o espaço ficcional tornou-se fundamental para discutirmos diversas questões contemporâneas, como a relação entre identidade e alteridade, o hibridismo, a desterritorialização, a migração e a imigração, a multiculturalidade, a espacialização na literatura e em outras artes, a espacialidade da linguagem literária, entre outras.

Como apontam Santos e Oliveira, "o espaço é esse conjunto de indicações concretas ou abstratas - que constitui um sistema variável de relações". ${ }^{1}$ Tais relações podem ser de ordem geográfica, histórica, social, psicológica, discursiva, etc.:

\footnotetext{
Assim sendo, se criamos uma personagem ficcional, vamos posicioná-la relativamente a outros elementos de nosso texto. Podemos situá-la fisicamente (criamos um espaço geográfico), temporalmente (definimos um espaço histórico), em relação a outras personagens (determinamos um espaço social), em relação às suas próprias características existenciais (concebemos um espaço psicológico), em relação a formas como essa personagem é expressa e se expressa (geramos um espaço de linguagem), e assim por diante. ${ }^{2}$
}

\footnotetext{
${ }^{1}$ SANTOS; OLIVEIRA. Sujeito, tempo e espaço ficcionais, p. 67.

${ }^{2}$ SANTOS; OLIVEIRA. Sujeito, tempo e espaço ficcionais, p. 67- 68.
} 
Além disso, o espaço na literatura implica também a maneira como o autor pretende criar sua obra em relação à realidade. Como ressalta Compagnon,

os textos de ficção utilizam, pois, os mesmos mecanismos referenciais da linguagem não ficcional para referir-se a mundos ficcionais considerados como mundos possíveis. Os leitores são colocados dentro do mundo da ficção e, enquanto dura o jogo, consideram esse mundo verdadeiro, até o momento em que o herói começa a desenhar círculos quadrados, o que rompe o contrato de leitura, a famosa "suspensão voluntária da incredulidade". ${ }^{3}$

Essa relação do ficcional com a realidade, de acordo com Santos e Oliveira, pode se estabelecer de duas formas, basicamente: a literatura se apresentaria ou "como um espelho plano, alimentando a ilusão de que é capaz de mostrar a realidade como ela é", ${ }^{4}$ como no caso do Realismo, ou "como espelho deformante, com a intenção de deslocar a imagem que a sociedade tem de si mesma". ${ }^{5}$ O caso que pretendemos apresentar a seguir se enquadra justamente nesta última forma, muito presente na contemporaneidade.

Portanto, ao refletirmos sobre a noção de espaço ficcional, necessitamos ativar uma série de outras categorias, dentre elas: a memória, quando lidamos com a representação de um espaço do passado; a mimese, quando estiver em jogo a crença na possibilidade de representação da realidade; a topografia, quando nos depararmos com um determinado tipo de espaço, como, por exemplo, o urbano; a sociedade, quando enfocarmos os elementos sociais que constituem um determinado espaço, uma vez que "escrever é esboçar mapas dos espaços sociais, investigar a instabilidade desses mapas e a dimensão ficcional de tais espaços" ${ }^{6}$ Pois, sem dúvida, como aponta Santos, o movimento humano é determinante para a configuração ficcional do próprio espaço urbano, de modo que devemos considerar "os deslocamentos do social na sua interação com o espaço físico urbano". ${ }^{7}$ Com isso, não corremos o risco de delimitar a noção de espaço apenas do ponto de vista do seu uso e funcionalidade, de modo que, no âmbito da ficção, se proporia como mero cenário diante do qual a ação se desenrola, mas também a ampliamos no sentido de que o espaço é determinante da própria ação.

A cidade é, talvez, o espaço mais privilegiado na contemporaneidade. Segundo Ravetti, trata-se de "uma espacialidade na qual participam as práticas sociais e as simbólicas e imaginárias, emolduradas na paisagem". ${ }^{8}$ Isso tem implicações também para o modo como se costuma lidar ficcionalmente com o espaço urbano, que vai desde a aprovação eufórica à completa rejeição por parte daquele que o vivencia:

Acuadas pelas contingências no meio das quais nascem e se desenvolvem, as pessoas projetam e reproduzem seu próprio habitat nos territórios da imaginação e andam, órfãs e carentes, procurando representações que dêem sentido e conformem a realidade na qual vivem. Nomear e representar as cidades, ser acolhido ou rejeitado, encontrar um espaço

\footnotetext{
${ }^{3}$ COMPAGNON. O demônio da teoria, p. 136-137.

${ }^{4}$ SANTOS; OLIVEIRA. Sujeito, tempo e espaço ficcionais, p. 72.

${ }^{5}$ SANTOS; OLIVEIRA. Sujeito, tempo e espaço ficcionais, p. 73.

${ }^{6}$ SANTOS. Paul Auster topógrafo: o espaço urbano contemporâneo, p. 107.

${ }^{7}$ SANTOS. Paul Auster topógrafo: o espaço urbano contemporâneo, p. 115.

${ }^{8}$ RAVETTI. De Moscou a ... Marte, p. 47.
} 
que permita desenvolvimentos que as completem, muitas vezes, induz as pessoas a representá-las como os lugares da felicidade ou povoadas de monstros, sinistros e rarefeitos, perigosos e fascinantes. ${ }^{9}$

De acordo com Santos, "para a leitura do texto da cidade, é preciso considerar a relação entre espaço e uso social como uma relação de determinação recíproca. Sociedade e espaço: mediação, interpretação e tradução mútuas". ${ }^{10}$ No espaço urbano, regem outros elementos que, na atualidade, geram uma "dimensão caracterizada por uma flutuação maior de sentidos, por uma indeterminação maior e maior descrença do poder de representação plena da realidade". ${ }^{11}$ Sendo assim, constata-se uma tendência anti-mimética no modo de lidar ficcionalmente com o espaço urbano, seja pela necessidade de se produzir efeito de simultaneidade e de dispersão da apreensão do espaço pelos sentidos, seja pela reconstrução do espaço pela memória, que pode se comportar justamente como um fator determinante para aquela literatura que não se pretende como "espelho plano", mas sim como "espelho deformante". Cabe-nos lembrar que, como afirma Santos, "inventar não é propor uma ordem falsa, incompatível com a ordem do real, mas, ao contrário, é afetar o real, explorar o que o real tem de maleável, ampliando as margens de sua mutabilidade". ${ }^{12}$

Outro fator a ser considerado diz respeito ao espaço urbano não como algo estático e delimitado em si, mas sim fluido e dinâmico, em que interagem diversas relações possíveis. Não se trata apenas da materialidade do próprio espaço, mas também do seu preenchimento por aqueles que nele se movem e agem:

A cidade não é apenas a concretude dos espaços visíveis - casas, edifícios, vias, parques, praças -, mas aquilo que nesses espaços circula. É, sobretudo, os fluxos segundo os quais interagem seres, objetos e vivências. Substitui-se, assim, uma visão substancialista de espaço por outra na qual o espaço é entendido como um conjunto de relações. É nesse sentido que se pode dizer que toda cidade é regida por uma gramática. ${ }^{13}$

Isso se deve parcialmente ao fato de que a cidade, enquanto espaço, é perpassada também por relações de ordem lingüística e discursiva: "Falando da cidade, estamos fazendo vir à tona a forma como seus espaços determinam nossa fala: ressonâncias, linhas melódicas, sutilezas de sotaque, estilos de persuasão - a cidade falando através de nós". ${ }^{14}$ Além disso, como frisa Santos, "o que mais interessa na ficção não é a delimitação dos espaços, não é a ação de situar-se, de localizar-se, mas sim a conjugação dos espaços, a ação de produzir um deslocamento, de constituir um fluxo contínuo de movimento, de instaurar uma dinâmica dos espaços". ${ }^{15}$ Pois

\footnotetext{
${ }^{9}$ RAVETTI. De Moscou a ... Marte, p. 47-48.

${ }^{10}$ SANTOS. Paul Auster topógrafo: o espaço urbano contemporâneo, p. 115-116.

${ }^{11}$ SANTOS. Paul Auster topógrafo: o espaço urbano contemporâneo, p. 116.

${ }^{12}$ SANTOS. Paul Auster topógrafo: o espaço urbano contemporâneo, p. 119.

${ }^{13}$ SANTOS. Um cachorro corre na cidade vazia, p. 148.

${ }^{14}$ SANTOS. Um cachorro corre na cidade vazia, p. 148.

${ }^{15}$ SANTOS. Paul Auster topógrafo: o espaço urbano contemporâneo, p. 120.
} 
efetuar a topografia do espaço contemporâneo só se torna possível ao se voltar para esse horizonte, que é, sempre, um espaço além, um espaço não-nosso, um espaço que transborda das fronteiras reconhecíveis, o espaço da identidade incerta, o espaço que não ocupamos, mas que insistentemente nos acena a distância. ${ }^{16}$

A seguir, apresentaremos um exemplo de espacialização ficcional, tendo por referência as noções e conceitos até aqui propostos. Trata-se de um espaço urbano - a antiga Berlim Oriental -, ou melhor, de um espaço dentro do espaço urbano: a "Alameda do Sol" (Sonnenallee). Ainda fomos imprecisos, pois isso vai mais além: de um espaço dentro de um espaço dentro do espaço urbano: "O extremo mais curto da Alameda do Sol" (Am Kürzeren Ende der Sonnenalle).

A delimitação do espaço, tendendo a uma espécie de miniaturização do universo representado ficcionalmente, possui uma tradição na literatura de língua alemã. O romance Berlin Alexanderplatz (1929), de Alfred Döblin, que tem como espaço uma praça no coração proletário da Berlim nos anos 20, o conto Unter den Linden (1974), da escritora Christa Wolf, delimitado espacialmente por uma das principais avenidas da antiga Berlim Oriental, e o romance Die Gelbe Straße (1934; "A Rua Amarela"), da escritora austríaca Veza Canetti, cujo universo se reduz a uma rua do Leopoldtstadt, antigo bairro judeu de Viena, são alguns exemplos desse tipo de espacialização em miniatura. Essas obras têm como característica semelhante a delimitação do raio de ação das personagens, como se todas as forças convergissem para esse núcleo espacial. Em todas elas, a vida gira em torno da topografia urbana reduzida a espaços interiores e exteriores de uma única rua ou praça, que, todavia, forma uma totalidade e se torna, com isso, onipresente, determinando as ações e as condições sociais de existência num universo diminuto.

\section{A construção ficcional do espaço da interdição: O Muro de Berlim e a "Alameda do SOL"}

Quando nos vem à mente o Muro de Berlim, logo pensamos num espaço limítrofe, espaço da cisão e, ao mesmo tempo, da interdição: interdição de ir e vir, de se expressar, de agir, de protestar, etc. No contexto da Guerra Fria, o mundo se polarizava entre blocos ideologicamente concorrentes. Se há um espaço geopolítico em que, por décadas, tais blocos puderam estender suas influências, tornando-o uma espécie de "tabuleiro de xadrez", esse espaço foi o da Alemanha dividida. Se reduzirmos esse espaço ainda mais, chegamos à cidade de Berlim, dividida desde 1945 em setores de ocupação, de acordo com as determinações da Conferência de Potsdam, e que se constituiria também em dois blocos: Berlim Ocidental, formada a partir dos setores de ocupação francês, britânico e americano e território da RFA - República Federal da Alemanha - desde 1949; Berlim Oriental, antigo setor de ocupação soviética, que se tornou a capital da RDA - República Democrática Alemã - em 1949.

Em 13 de agosto de 1961, no auge da crise entre os blocos, o Governo da RDA ordenou a construção de um muro, chamado, no jargão oficial do "Estado dos Trabalhadores e

${ }^{16}$ SANTOS. Paul Auster topógrafo: o espaço urbano contemporâneo, p. 122. 
Camponeses" (Arbeiter- und Bauernstaat), de "Parede de Proteção Anti-Fascista" (Antifaschistischer Schutzwall). Tal "parede" foi acompanhada de outros "dispositivos" que visavam, sobretudo, a impedir o êxodo de mão-de-obra qualificada rumo ao Ocidente. Torres de vigia, check points, bloqueios com arame farpado, a "faixa da morte" (Todesstreifen), um banco de areia que deveria dificultar a fuga e denunciar as pegadas de todos aqueles que se aproximassem do muro, compunham esse cenário repressor. Mas, como o espaço não é apenas um mero "cenário", ali foram postadas unidades da "Polícia Popular" (Volkspolizei), cujos soldados eram chamados, no linguajar popular, de Vopos. Geralmente, tais unidades eram compostas por soldados de outras regiões da Alemanha Oriental que não Berlim, pois se acreditava que, com isso, eles não hesitariam em atirar naqueles que tentassem fugir. ${ }^{17}$

Podemos reduzir ainda mais a perspectiva espacial, se pensarmos que a Berlim dividida produziu outras divisões: divisões nas relações humanas - separando parentes, famílias e amigos - e divisões topográficas. Um desses casos é o da "Alameda do Sol" (Sonnenallee), uma rua de Berlim que se tornaria a miniatura do processo de cisão entre as duas Alemanhas: em cerca de cinco quilômetros de extensão, os números de 1 a 370 ficavam do lado ocidental da cidade, e os de 379 a 411, ou seja, apenas os últimos sessenta metros, do lado oriental: entre os segmentos da rua, localizavam-se o muro e o checkpoint. Pois é justamente esse espaço concreto e reduzido que o escritor alemão Thomas Brussig tomou como referência para constituir o espaço ficcional no romance Am Kürzeren Ende der Sonnenallee ("No extremo mais curto da Alameda do Sol").

O processo histórico que culminou com a Queda do Muro de Berlim, em 09 de novembro de 1989, e com a conseqüente reunificação alemã, oficialmente celebrada em 03 de outubro de 1990 - período da chamada Wende ("mudança", "transição") - tem sido objeto de obras tanto no âmbito da literatura quanto do cinema. Uma vertente expressiva se formou, sobretudo, em torno da maneira como jovens autores e cineastas, que nasceram e cresceram na antiga Alemanha Oriental, vêem seu próprio passado. Ao interpretarmos o romance Am Kürzeren Ende der Sonnenallee, visamos, justamente, apresentar o exemplo mais significativo dessa vertente, no intuito de refletir sobre o papel do espaço para a construção de uma memória que se orienta pela tentativa de "dominar o passado" (no sentido do conceito alemão de Vergangenheitsbewältigung), com todas as implicações que um regime totalitário pode impingir à sociedade em termos de cerceamento da liberdade, censura, violência, etc.

Quando falamos do romance Am Kürzeren Ende der Sonnenallee ("No extremo mais curto da Alameda do Sol"), de Thomas Brussig, não podemos deixar de mencionar também o filme Sonnenallee ("Alameda do Sol"), dirigido por Leander Haußmann, cujo roteiro é de autoria de ambos. Na verdade, se trata de uma relação atípica, pois o filme não é uma adaptação do romance, mas sim o contrário: o excesso de material que havia sido utilizado para compor o roteiro serviu de base para que Thomas Brussig escrevesse o romance. Isto acaba gerando uma outra implicação: às vezes sentimos necessidade de recorrer também ao filme como ponto de partida para discutirmos os processos de espacialização no romance, publicado em setembro de 1999, um mês antes da estréia do

${ }^{17}$ Cf. KENNTEMICH. Das war die DDR. Eine Geschichte des anderen Deutschland, p. 15-17. 
filme, que ocorreu no dia 07 de outubro do mesmo ano, data em que a República Democrática Alemã completaria 50 anos (se ainda existisse).

No contexto de lançamento do filme, Thomas Brussig definiu-o como uma "comédia do Muro", visão que também foi partilhada pela crítica. Em resenha publicada no jornal taz, Christiane Kühl fala de um "filme de recordação", destacando-o como "a primeira farsa do Muro". ${ }^{18}$ No mesmo sentido, o romance de Thomas Brussig foi considerado pela crítica uma "nostalgia de fina qualidade sobre a RDA", ${ }^{19}$ conforme aponta Volker Hage, num artigo publicado na revista Der Spiegel, e como "a mais pura, alegre, terna poesia de resistência”, ${ }^{20}$ conforme ressalta Andreas Nentwich, em resenha publicada no jornal Die Zeit. Já para Thomas Schuldt, em resenha publicada no jornal Rheinischer Merkur, o romance apresenta mais do que um caráter apenas "ostálgico": é também "uma imagem satírica e grotesca da sociedade da RDA". ${ }^{21}$ No mesmo sentido, Mechthild Küpper, em resenha que publicou no jornal FAZ (Fankfurter Allgemeine Zeitung) afirma que "[o] autor, nascido em 1965, tornou-se um especialista em escrever de maneira leve e humorada sobre a RDA, sem reduzi-la nostalgicamente". ${ }^{22}$

Além disso, para Thomas Brussig, escrever romances sobre o cotidiano na RDA é uma forma de lidar com o próprio passado. Nascido em Berlim Oriental, no ano de 1965, o escritor iniciou sua carreira literária em 1991, com o romance Wasserfarben ("Aquarelas") e obteve reconhecimento por parte da crítica com o romance Helden wie wir ("Heróis como nós”), de 1995. Mas é com Am Kürzeren Ende der Sonnenallee que ele se verá em meio a um debate em torno do tema "ostalgia" (Ostalgie, termo composto de Ost - Oriente e Nostalgie - nostalgia), uma postura nostálgica em relação a seu passado vivenciado na Alemanha Oriental. Entretanto, o próprio Thomas Brussig aponta o aspecto biográfico como fundamental para a elaboração de um quadro ficcional do passado na RDA:

Minha infância se passou na RDA. Por isso, não devo me recordar de minha infância com prazer? Também escrevi "No extremo mais curto da Alameda do Sol" porque levei a sério a nostalgia. Ele se tornou um livro muito afetivo. Eu sempre dizia: ele deve se tornar um livro que, ao lê-lo, até mesmo alemães ocidentais sintam inveja de não terem sido permitidos viver na RDA. Já nessa pretensão há algo enviesado. Um historiador não deveria se ocupar desse livro. ${ }^{23}$

Portanto, o modo como o próprio autor imagina o processo literário de criação de uma obra sobre o passado na RDA - a partir de sentimentos nostálgicos - nos parece adequado ao conceito de "espelho deformante", ${ }^{24}$ proposto por Santos e Oliveira. Como poderemos constatar, isso terá conseqüências para a espacialização no romance.

\footnotetext{
${ }^{18}$ KÜHL. Sex und Substitutionsdrogen, p. 15.

${ }^{19}$ HAGE. Der Westen küsst anders, 1999a.

${ }^{20}$ NENTWICH. Zärtliche Poesie des Widerstands. Thomas Brussig widmet sich den Ostberliner Helden der "Sonnenallee".

${ }^{21}$ SCHULDT. Zoni macht Winkewinke. Zwischen Ostalgie und Ironie, Pathos und Pointen: Irrungen und Wirrungen der Heranwachsenden im Arbeiter- und Bauernstaat.

${ }^{22}$ KÜPPER. Sieben leere Patronen am Ende der Nacht, p. L4.

${ }^{23}$ BRUSSIG. Herr Brussig, was halten Sie von Nostalgie? Entrevista concedida a Silke Lambeck. Tradução nossa.

${ }^{24}$ SANTOS; OLIVEIRA. Sujeito, tempo e espaço ficcionais, p. 73.
} 
Tanto no romance quanto no filme a RDA aparece em meio às recordações do protagonista - Michael, um adolescente chamado carinhosamente por todos de "Micha" - sobre sua juventude nos anos 70. Com humor sarcástico, em meio a figuras caricatas e estereótipos, Thomas Brussig expõe os absurdos de um sistema que controlava os cidadãos em todas as esferas de suas vidas. Enquanto o Estado e as condições impostas por ele são apresentados em cenas bizarras, ou mesmo grotescas, numa tentativa do autor em se reconciliar com o passado, aparecem também algumas facetas do cotidiano, festas, discos de músicas proibidas, e as relações amorosas num grupo de jovens. A espacialização ficcional, baseada na cisão concreta e na existência real da Sonnenallee, funciona como uma espécie de miniatura da divisão alemã, e o topônimo "Alameda do Sol" conota, de antemão, algo positivo. Isso fica explícito no modo como, de maneira humorada, Thomas Brussig justifica ficcionalmente a divisão da "Alameda do Sol", no romance:

[...] Michael Kuppisch pôde bem imaginar que também na Conferência de Potsdam, no verão de 1945, quando Josef Stalin, Harry S. Truman e Winston Churchill dividiram em setores a antiga capital do Reich, a menção da Alameda do Sol causou impacto. Sobretudo em Stalin; ditadores e déspotas são conhecidamente predestinados a arroubos poéticos. Uma rua com um nome tão bonito assim, Stalin não queria deixá-la para os americanos, pelo menos não totalmente. Assim, ele reivindicou junto a Harry S. Truman a Alameda do Sol - e ele, naturalmente, recusou. Todavia, Stalin não se deu por satisfeito e logo ameaçou chegar às vias de fato. Quando as pontas dos narizes de Stalin e de Truman já estavam quase se tocando, o primeiro-ministro britânico se enfiou entre eles, os separou e se postou diante do mapa de Berlim. À primeira vista ele viu que a Alameda do Sol tinha uma extensão superior a quatro quilômetros. Tradicionalmente, Churchill estava do lado dos americanos, e todos no recinto consideraram fora de cogitação que ele a concederia a Stalin. E, como se conhecia Churchill, ele daria uma tragada em seu charuto, refletindo por um momento, soltaria a fumaça, balançaria a cabeça negativamente, e passaria para o próximo ponto de negociação. Porém, quando Churchill tragou em seu charuto, ele notou, para seu desgosto, que ele já estava apagado. Stalin foi tão solícito ao acender-lhe o charuto, que enquanto Churchill se deliciou com a sua primeira tragada e se curvou sobre o mapa de Berlim, ele imaginou uma forma de revidar adequadamente ao gesto de Stalin. Quando Churchill soltou novamente a fumaça, ele concedeu a Stalin uma ponta de sessenta metros da Alameda do Sol e mudou de tema.

Deve ter sido assim, pensou Michael Kuppisch. Senão como pode uma rua tão longa ter sido ainda dividida um pouco antes do seu final? E, às vezes, ele também pensava: se o imbecil do Churchill tivesse prestado atenção em seu charuto, hoje nós estaríamos vivendo no lado ocidental. ${ }^{25}$

Essa passagem, logo no início do romance, nos permite uma série de conjecturas. Se por um lado, historicamente, a Alameda do Sol de fato foi dividida, por outro, Thomas Brussig ficcionalizou, em tom de ironia e humor, o suposto motivo para tal divisão. Com isso, ele emprestou ao espaço, em sua relação geográfica, um sentido de arbitrariedade, a qual é justamente questionada pelo protagonista. Além disso, a redução espacial pela ficção acaba por produzir um efeito que não é costumeiro na construção ficcional do espaço urbano. Ao invés de um espaço marcado pela dispersão dos sentidos, estimulados por múltiplas sensações visuais, sonoras e auditivas, a atmosfera da "Alameda do Sol" se

\footnotetext{
${ }^{25}$ BRUSSIG. Am Kürzeren Ende der Sonnenallee, p. 7-8. Tradução nossa.
} 
assemelha mais àquela de uma pequena aldeia, numa rua minúscula e esquecida, onde só trafegam algumas poucas pessoas e veículos.

Sem dúvida, tanto o romance quanto o filme se constroem a partir da sátira, da graça, da ironia, do burlesco e do caricato, que têm o poder de despertar o riso. A comicidade se configura na constituição das personagens e na relação que elas estabelecem entre si e com o espaço do "extremo mais curto da Alameda do Sol". O esquema abaixo apresenta a configuração das relações das personagens em quatro âmbitos, tendo o protagonista em seu centro:

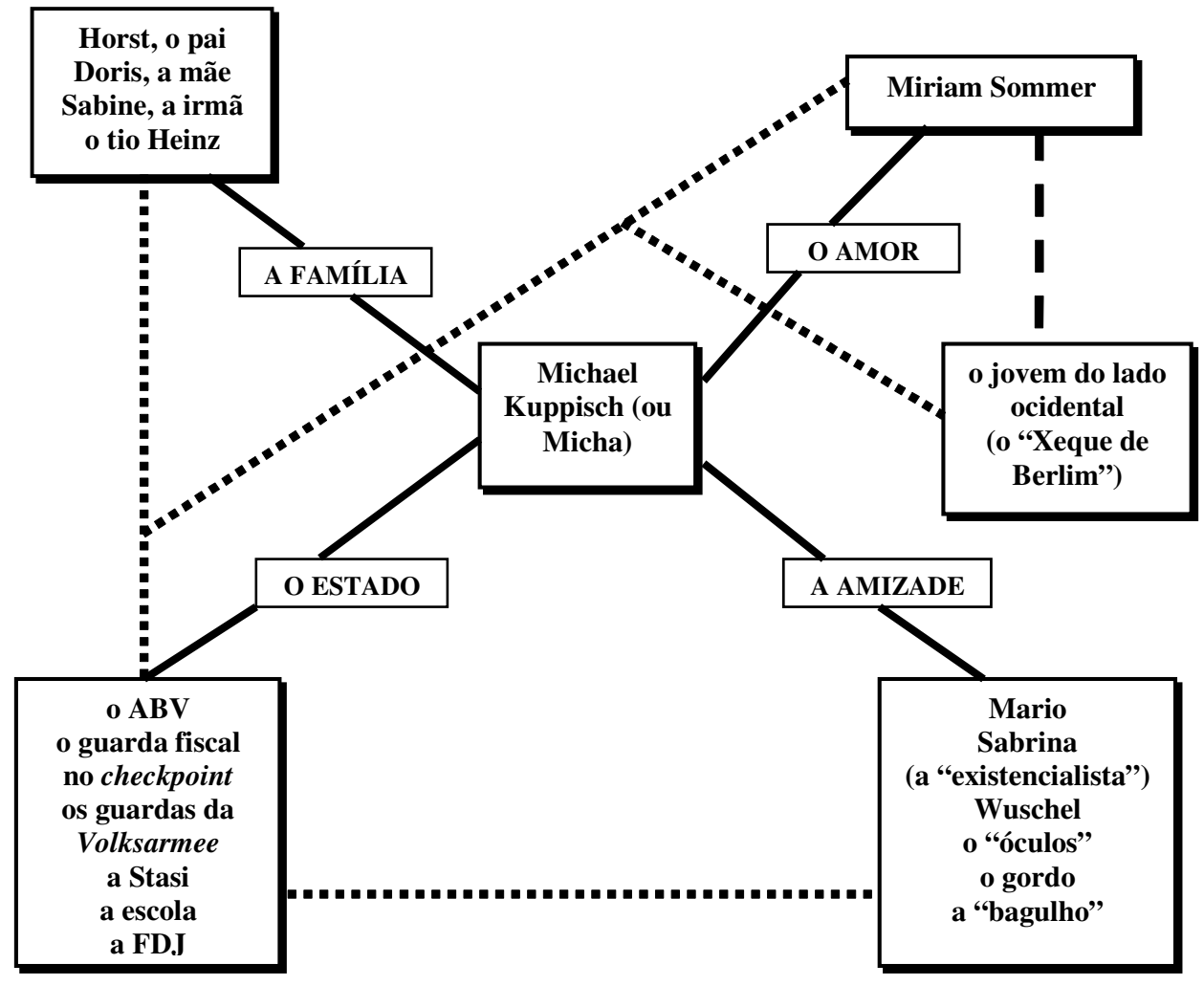

Como dito anteriormente, a história é narrada de maneira nostálgica, a partir das lembranças da adolescência de Michael - Ehrenreich no filme, e Kuppisch no romance - e pode ser sistematizada em quatro âmbitos distintos de relação: a família, o Estado, o amor e a amizade. Enquanto o filme tem em seu centro Michael, que, em determinadas passagens, figura como o próprio narrador em off, o romance é narrado em terceira pessoa do singular e contém histórias que destacam outras personagens, como é o caso da relação amorosa entre Mario e Sabrina (a "existencialista"). Por questões de delimitação temática em torno da espacialização, nos ateremos, a seguir, apenas ao âmbito do Estado e sua influência para a configuração espacial.

Em ambas as obras, o cerceamento da liberdade se expressa topograficamente pela existência de diversos mecanismos de delimitação, vigilância e repressão: o muro, a "faixa da morte" (Todesstreifen), o checkpoint, as torres de observação, o bloqueio com arame farpado e as metralhadoras postadas. Já o período histórico representado em relação ao espaço, ou seja, meados dos anos 70, se caracteriza, por um lado, pelo cotidiano de pessoas simples que moram na "Alameda do Sol" e, por outro, pela "pequena" guerra 
empreendida pela maioria contra soldados e professores fiéis à linha partidária do Estado. Entretanto, o espaço opressor é constantemente enfraquecido pelo humor.

Além dos elementos espaciais em sua relação topográfica e histórica, o âmbito de relações do Estado com os cidadãos que moram no "extremo mais curto da Alameda do Sol" se configura ficcionalmente pela presença de algumas personagens estereotipadas, dentre elas: o suboficial Horkefeld; o ABV - Abschnittsbevollmächtigte, uma espécie de "controlador do setor" -; o guarda fiscal no checkpoint; os guardas da Volksarmee (o "Exército do Povo"); a Stasi - Staatssicherheitsdienst (o "Serviço de Segurança do Estado", polícia secreta da RDA); as professoras, como a Sra. Nitzhold, fiel ao programa do partido SED - Sozialistische Einheitspartei Deutschlands ("Partido da Unidade Socialista da Alemanha"); e a organização juvenil FDJ - Freie Deutsche Jugend ("Juventude Alemã Livre"). Em geral, a imagem dos aparelhos de ideologia, de segurança e de repressão do Estado, construída ficcionalmente, tanto no romance quanto no filme, não aparece de maneira incisiva, mas pela sua onipresença de caráter totalitário, abarcando todos os âmbitos da relação social entre as personagens, conforme foi apontado anteriormente no esquema.

Para podermos ilustrar a produção do efeito de riso em ambas as obras, como forma de se "dominar o passado" e, ao mesmo tempo, de enfraquecimento do espaço de interdição, selecionamos quatro cenas. Na primeira delas, extraída do filme, Michael escreve diários "falsos" para impressionar a bela Miriam, a nova colega de classe por quem está apaixonado, emprestando ao relato não só um caráter de permanente aventura e perigo num Estado totalitário, mas também de tomada de consciência política. Ao elaborar um dos "apontamentos", Micha, por assim dizer, "lapida” o vocabulário:

Agora, eu tenho quatorze anos e acabo de receber a minha carteira de identidade. A partir de agora sou apenas um algarismo... Número, sou apenas um número... Um número num... Número de identificação... Número de identificação num sistema desumano. ${ }^{26}$

Nessa passagem, podemos considerar a relação da linguagem com o espaço e, ao mesmo tempo, uma relação psicológica da personagem com esse mesmo espaço, pois se trata de uma narrativa dentro da narrativa. O tom crítico dos apontamentos de Micha demonstra que ele é consciente do espaço topográfico opressor; porém, sua relação social com o espaço de interdição demonstra uma postura de subjugado. Com isso, o tom crítico se torna relativo para o leitor, pois este pode confrontar os apontamentos dos "falsos diários" de Micha com suas próprias atitudes - sua intenção é de impressionar Miriam, criando uma imagem de coragem. Deste modo, podemos afirmar que, conforme ressalta Santos, ${ }^{27}$ constata-se uma relação entre espaço e uso social como uma relação de determinação recíproca, pois assim como Micha sabe o que o espaço, na sua relação topográfica opressora, significa, ele constrói uma imagem "favorável" de si a partir de um "enfrentamento" desse mesmo espaço, mesmo que apenas em seus "falsos diários". Noutro "apontamento", identificamos o mesmo procedimento: Micha afirma planejar uma fuga. Para isso, pretendia cavar um túnel e fundar o seu próprio grupo de resistência:

\footnotetext{
${ }^{26}$ HAUBMANN. Sonnenallee. Tradução nossa.

${ }^{27}$ SANTOS. Paul Auster topógrafo: o espaço urbano contemporâneo, p. 115-116.
} 
Esse país pressiona feito sapatos apertados. A gente não pode se mover, apenas sonhar. [...] Decidi cavar em direção ao Ocidente... Escuridão... Vejo luz no fim do túnel... Suor de medo... O suor gélido de medo escorre pela minha testa no momento em que olho os canos ameaçadores das metralhadoras soviéticas. ${ }^{28}$

A cena correspondente no romance não recebe a mesma dimensão crítica, da ficção dentro da ficção. Ao contrário, o relato crítico é neutralizado pela ênfase em relação ao ato mesmo de escrever os "diários":

O primeiro diário foi o mais difícil, pois Micha precisou escrevê-lo com a mão esquerda, para que a escrita ainda parecesse desajeitada. O efeito de seus diários sobre Miriam seria ainda maior, quanto mais longo fosse o período em que ele fizesse seus apontamentos, calculou Micha. A noite toda Micha escreveu seus diários e refletiu sobre o que significaria viver ali, no extremo mais curto da Alameda do Sol, onde as coisas transcorrem do modo que transcorrem. E ele escreveu que sempre a amou porque sentiu que Miriam é algo especial e que nela vive algo que a excede, e que ela sempre lhe deu esperança e ele the deseja tudo, tudo, que ela consiga tudo. Ele sabia que leria todas as suas confissões a ela, mas isso não lhe importava. Para impressionar Miriam, para salvá-la, todos os meios lhe pareciam legítimos. Todos.

Na manhã seguinte, a senhora Kuppisch encontrou Micha do jeito como ele havia adormecido debruçado sobre o último diário. A cabeça de Micha jazia sobre o diário aberto, suas mãos estavam sujas de tinta e sete cargas de caneta vazias estavam sobre a mesa. Isso mesmo, sete! Enquanto Gengis Kahn gerou em uma única noite sete filhos, Micha gastou em uma noite sete cargas de caneta. ${ }^{29}$

Mesmo que Micha, no romance, reflita sobre o significado de viver no extremo mais curto da Alameda do Sol, "onde as coisas transcorrem do modo que transcorrem", suas palavras deixam implícitas as dificuldades de viver num Estado totalitário, ficcionalmente miniaturizado pelo autor.

$\mathrm{Na}$ segunda cena, tomada como exemplo da relação entre espaço topográfico de interdição e espaço social, ocorre um curto-circuito em todo o sistema elétrico no setor do muro, provocado por um guarda fiscal do checkpoint. No filme, quando o guarda fiscal liga um aparelho de som de marca japonesa, que havia sido apreendido, para demonstrar a Heinz (pequeno "contrabandista" de Berlim Ocidental e tio de Micha) que o rádio "Minetta" (no romance, "Fichtelberg"), de fabricação da Alemanha Oriental, seria tecnicamente superior, tudo fica escuro na "faixa da morte", ao longo do muro, e no checkpoint. Em tom de ironia, o guarda fiscal une "dois sistemas", e o curto-circuito se torna metáfora do próprio "curto-circuito" nas relações entre Ocidente e Oriente durante a chamada "Guerra Fria". Já no romance, além de serem duas cenas distintas, uma na qual o guarda fiscal exibe o "rádio oriental" ao tio Heinz ${ }^{30}$ e outra em que ocorre o curto-circuito, ${ }^{31} \mathrm{o}$ momento de agitação nas proximidades do muro é apresentado da seguinte forma:

A queda de energia veio exatamente no momento em que o guarda fiscal conectou o complicado aparelho estéreo hi-fi, de fabricação japonesa, à rede de energia da Alemanha Oriental. Houve um curto - e a luz de toda a área residencial e da faixa da morte apagou.

\footnotetext{
${ }^{28}$ HAUBMANN. Sonnenallee. Tradução nossa.

${ }^{29}$ BRUSSIG. Am kürzeren Ende der Sonnenallee, p. 147-148. Tradução nossa.

${ }^{30}$ Cf. BRUSSIG. Am kürzeren Ende der Sonnenallee, p. 59-61.
} 
Versado em teorias conspiratórias, o fiscal concluiu feito um raio que o aparelho hi-fi japonês era uma espécie de Cavalo de Tróia, que fora propositalmente colocado nas mãos do pessoal da aduana a fim de provocar uma queda de energia. E, por isso, o guarda fiscal disparou imediatamente o alarme geral. Ele gritou "Alarme na fronteira!" e disparou munição luminosa para o céu, onde se via a lua cheia, à qual, provavelmente, se devia o fato de que, naquela noite, todos estavam mais agitados do que de costume. ${ }^{32}$

Com isso, se instala a tensão. No filme, Wuschel, que finalmente comprara de um contrabandista o disco do Rolling Stones, Exile on Main Street (1972), foge dos soldados do "Exército do Povo", pois teme que eles lhe confisquem o álbum contrabandeado. Ele acaba sendo alvejado por um tiro, disparado pelo suboficial Horkefeld. Mas, mantendo o tom hilário que perpassa tanto o romance quanto o filme, a aparente tensão da cena é rompida pelo seu desfecho: a bala alojara-se dentro da capa dos discos, que Wuschel tentava esconder debaixo de sua jaqueta, salvando-o da morte certa. Ele, no entanto, ao ver seu "objeto de desejo" quebrado pelo tiro, chora de desespero: "E agora ambos estão quebrados. Era um álbum duplo!”33 No romance, temos a seguinte descrição da mesma cena:

[...] Wuschel estava caído na rua, não se mexia, e todos choravam. Na altura de seu coração, o balaço perfurou a jaqueta. Todos sempre tiveram a esperança de nunca ter de vivenciar algo como aquilo. Mas aconteceu. Wuschel ainda se movia. A existencialista abaixou-se para, pelo menos, lhe confortar no momento da morte. Mas, de repente, Wuschel se endireitou. Ele desabotoou sua jaqueta e, ainda bem atordoado, apanhou o Exile on Main Street. O disco estava varado pela bala, mas ele havia lhe salvado a vida.

Wuschel começou a chorar.

"A edição inglesa autêntica!", ele disse, em prantos, ao puxar da capa rasgada os cacos do Exile. "Era novo! E lacrado! E agora ambos estão quebrados! Era um álbum duplo!" Wuschel se desfez em lágrimas. ${ }^{34}$

Podemos dizer que a relação psicológica com o espaço de interdição se reflete também nas ações de Wuschel e sua obstinação em obter o disco proibido dos Rolling Stones. Não é por acaso que Thomas Brussig tenha construído essa personagem justamente com apenas um objetivo: obter, a qualquer preço, o álbum Exile on Main Street, de 1972. O disco, por assim dizer, empresta também um sentido de exílio àqueles que estão morando no extremo mais curto da "Alameda do Sol".

Por sua vez, na terceira cena selecionada para análise, reconhecemos, de certo modo, a banalização do espaço de interdição a partir das atitudes de Micha e Wuschel. Trata-se, aliás, de uma cena que está presente apenas no romance e, portanto, pertence àqueles materiais que não foram aproveitados por Thomas Brussig e Leander Haußmann na redação do roteiro. Na cena em questão, Micha tenta recuperar uma carta de amor que tinha recebido de Miriam, mas que tinha voado quando ele fora abordado repentinamente na rua pelo $\mathrm{ABV}$, indo parar justamente na "faixa da morte". Para isso, contou com a ajuda de Wuschel:

\footnotetext{
${ }^{31}$ Cf. BRUSSIG. Am kürzeren Ende der Sonnenallee, p. 141-143.

${ }^{32}$ BRUSSIG. Am kürzeren Ende der Sonnenallee, p. 141. Tradução nossa.

${ }^{33}$ HAUBMANN. Sonnenallee. Tradução nossa.

${ }^{34}$ BRUSSIG. Am kürzeren Ende der Sonnenallee, p. 143. Tradução nossa.
} 
[...] "Lá atrás está a carta dela, você entende, a carta dela, e eu não posso chegar lá!" "Mas como assim, não pode?", Wuschel o interrompeu admirado.

"Mas como não?", perguntou Micha desesperado. "Ali é a faixa da morte. Cara, se você entrar lá, você será fuzilado."

$[\ldots]$

"Lá está o teu apartamento!"

"E daí, isso eu sei!" disse Micha, e não conseguia entender o que Wuschel queria dizer com aquilo.

"E daí é que com uma extensão você pode ligar aqui o teu aspirador de pó."

"E daí? O que eu devo fazer logo aqui com um aspirador de pó?"

Wuschel apontou para uma elevação formada com restos de construção, que jazia há anos diante do prédio em que Micha morava. Em meio aos escombros estava preso um longo pedaço de mangueira. "Você só precisa unir uma extremidade da mangueira ao aspirador de pó e segurar a outra na faixa da morte."

Micha ficou boquiaberto - a idéia era genial. Ele precisava apenas passar a mangueira algumas vezes no lugar próximo de onde a carta jazia. Em algum momento ela seria sugada e se prenderia à extremidade da mangueira. Imediatamente, Micha apanhou em seu apartamento um aspirador de pó e um rolo de extensão. Wuschel precisou ajudá-lo, embora a contragosto. ${ }^{35}$

Entretanto, o plano fracassa com a queda de energia e culmina com a cena em que Wuschel é alvejado. Atingida por uma das munições luminosas, a carta acabou sendo destruída pelo fogo. O que essa cena demonstra é a relação da personagem com o espaço opressor. Assim como o disco dos Rolling Stones se torna uma obsessão para Wuschel, a primeira carta de amor que Micha tinha recebido de Miriam, sem tê-la lido, também fez com que ele arriscasse até mesmo se aproximar da "faixa da morte" para tentar resgatá-la. E como uma marca que perpassa todo o romance, o episódio chega às raias do burlesco - mais uma vez, o perigo iminente é enfraquecido pelo humor e o riso.

Por fim, a última cena selecionada para interpretação corresponde ao final do filme, que se encerra como um musical na "Alameda do Sol", em que as pessoas se dirigem ao checkpoint para atravessá-lo rumo a Berlim Ocidental. Tecnicamente, a imagem é envelhecida, como se o tempo tivesse passado e não tivesse ficado ninguém para trás. A imagem em preto-e-branco é apoiada temática e simultaneamente pela trilha sonora, mais especificamente pela canção Du hast den Farbfilm vergessen ("Você esqueceu o filme colorido"), interpretada por Nina Hagen e com letra de Michael Heubach (tecladista do grupo Automobil), cujo refrão ilumina a questão da recordação e da pretensa "verdade" da imagem recordada:

Você esqueceu o filme colorido, Michael querido,

Agora ninguém acredita em nós, como aqui era belo (ha-ha)

(ha-ha) Você esqueceu o filme colorido, em minh'alma,

Tudo azul e branco e verde e, mais tarde, não era mais verdade!

Você esqueceu o filme colorido, em minh'alma,

Tudo azul e branco e verde e, mais tarde, não era mais verdade!"36

\footnotetext{
${ }^{35}$ BRUSSIG. Am kürzeren Ende der Sonnenallee, p. 139-140. Tradução nossa.

${ }^{36}$ HAGEN. Du hast den Farbfilm vergessen. Tradução nossa.
} 
Além disso, antes da execução da canção de Nina Hagen, ouvimos ainda a voz de Micha em off: "Era uma vez um país, no qual vivi; e se me perguntarem como era, direi: foi a mais bela fase de minha vida. Eu era jovem e estava amando". ${ }^{37}$ Portanto, estamos no âmbito do "faz-de-conta", dos "contos de fadas", com seu "era uma vez" (es war einmal...). Recordar, em tom de nostalgia, da vida num Estado totalitário, pressupõe um "espelho deformante".

Por sua vez, pela própria constituição que o diferencia do filme, pois não se sustenta nem na simultaneidade simbólica das imagens nem na trilha sonora, o romance se encerra de uma outra forma, com a seguinte mensagem do narrador em $3^{\underline{a}}$ pessoa:

Quem realmente quer conservar o que aconteceu não pode se render às recordações. A recordação humana é um processo agradável demais para apenas preservar o que passou. Ela é o oposto daquilo o que afirma ser. Pois a recordação pode muito, muito mais. Ela realiza, de maneira persistente, o milagre de selar uma paz com o passado, na qual todo rancor se esvai e o véu macio da nostalgia recai sobre tudo aquilo que foi percebido como incisivo e agudo.

Pessoas felizes têm uma péssima memória e ricas recordações. ${ }^{38}$

Confrontado com a questão de uma suposta "ostalgia" em sua obra, Thomas Brussig considera que "[à] nostalgia pertence aquilo que foi embora, passou, desapareceu, acabou". ${ }^{39}$ Em tom de defesa, ele chama a atenção para o seguinte fato:

Há grupos suficientemente "ostálgicos”. Porém, há tempos que não são tão políticos como parecem. Essas festas "ostálgicas" celebram o passado da mesma forma como o faz uma festa a caráter dos anos 70. A RDA sempre foi suficientemente inofensiva, de maneira que, hoje, de certa forma inocente, pode se fazer festa com seus símbolos. ${ }^{40}$

Com relação à ficcionalização do passado da RDA, Thomas Brussig considera que o próprio caráter de "recordar" algo já contenha em si um componente ficcional que desestabiliza qualquer crença na apresentação do "real" - inclusive espacialmente através de um "espelho deformante" - e auxilia aquele que recorda a "dominar" o passado de modo conciliatório:

Recordações não se interessam pelo que "realmente" foi. Elas iludem, enganam, adulam, ocultam. Na verdade, elas nos ajudam intimamente a nos tornarmos felizes. A ostalgia diferencia-se apenas em um ponto essencial da nostalgia tradicional: o objeto de transfiguração é dificilmente disputado no seu sentido. A RDA está sob pressão especial. A transfiguração precisa se distanciar de uma imagem histórica dominante do "terror da Stasi", do "Estado do SED”, do "regime totalitário", etc. Essa imagem histórica está em um canto morto do espaço de experiências de muitos alemães orientais. A RDA, na cabeça de muitos, é algo diferente daquilo que lhes é apresentado por historiadores - e também na TV.41

\footnotetext{
${ }^{37}$ HAUBMANN. Sonnenallee.

${ }^{38}$ BRUSSIG. Am Kürzeren Ende der Sonnenallee, p. 156-157. Tradução nossa.

${ }^{39}$ BRUSSIG. Der Brechreiz ist ein aktueller.

${ }^{40}$ BRUSSIG. Jubelfeiern wird's geben. Entrevista concedida a Volker Hage. Tradução nossa.

${ }^{41}$ BRUSSIG. Der Brechreiz ist ein aktueller. Tradução nossa.
} 
Portanto, "dominar o passado" de modo conciliatório, a partir de uma visada humorada em relação ao vivenciado na RDA, é, para Thomas Brussig, um aspecto que passa pelo tratamento dos acontecimentos recordados a partir de um processo que conteria em si algo de "ficcional", inclusive o próprio espaço e o conjunto de suas variações:

No livro, não se trata de mostrar a RDA como ela era, mas sim a maneira como as pessoas, hoje, se lembram dela. E eu descobri, durante o período em que escrevi o livro, que recordar e esquecer não são opostos, mas sim caminham lado a lado. A recordação é como um órgão psíquico, que digere o passado e nos ajuda a poder viver bem com aquilo o que foi. ${ }^{42}$

Além disso, Thomas Brussig procura distinguir entre a representatividade "fiel" daquilo o que teria sido a RDA enquanto país sob o regime de um Estado totalitário (descartada de antemão para a construção de sua obra) e a representatividade "ficcional" que tende não só ao enfraquecimento do caráter totalitário do regime do SED, mas também às necessidades pessoais de se reconciliar com esse mesmo passado, de modo que se tenha, ao final, um saldo "prazeroso" de recordações:

Recordar é sempre transfigurar, que caminha lado a lado com o ato de esquecer. A recordação da RDA é um espaço a ser conquistado. Nada impede que os alemães orientais se recordem do passado com prazer, mas uma coisa eles têm de saber: isto não torna a RDA melhor. $O$ fato de que, de repente, a RDA tenha tantos lados bons assim não se situa na RDA, mas na natureza do próprio ato de recordar. E se alemães ocidentais ouvem alemães orientais dizerem que gostam de se recordar dos tempos da RDA, não têm o direito de suspeitar que estes queiram tê-la de volta. ${ }^{43}$

Portanto, para o autor e roteirista, "filme e livro devem colaborar um pouco para a conciliação". 44 "Agora que já passou", afirma Brussig, "notamos de repente que a RDA se apropria muito bem ao ato de narrar em virtude de seus aspectos profanos e ridículos". ${ }^{45}$ E a atitude de não apresentar de modo incisivo o caráter repressor do Estado totalitário, e, com isso, abrir margem para uma mensagem conciliatória entre o presente daquele que recorda e o passado recordado, foi tomada conscientemente por Thomas Brussig: "Eu queria que o filme não trouxesse a história costumeira do sistema totalitário". ${ }^{46}$

\section{O espaço, O RISO e a "Ostalgia"}

Por fim, podemos afirmar que esse gesto "ostálgico" do autor ao lidar com a ficcionalização do passado na RDA tem implicações para o processo de espacialização. Os exemplos anteriormente apresentados ilustram diversas facetas desse processo. $\mathrm{O}$

\footnotetext{
${ }^{42}$ BRUSSIG. Nachdenken über Thomas B. Entrevista concedida a Volker Gunske e Sven S. Poser. Tradução nossa.

${ }^{43}$ BRUSSIG. Herr Brussig, was halten Sie von Nostalgie? Entrevista concedida a Silke Lambeck. Tradução nossa.

${ }^{44}$ BRUSSIG. Thomas Brussigs zweite Heldentat. Entrevista concedida a Axel Frohn. Tradução nossa.

${ }^{45}$ BRUSSIG. Jubelfeiern wird's geben. Entrevista concedida a Volker Hage. Tradução nossa.

${ }^{46}$ BRUSSIG. Sonnenallee. Entrevista concedida a Sandra Maischberger. Tradução nossa.
} 
espaço, enquanto conjunto de variações, basicamente se constitui dos seguintes componentes: geográfico ou topográfico (o muro, as instalações, a rua), histórico (os anos 70), social (as personagens), psicológico (os "diários" de Micha, a obsessão de Wuschel pelo disco dos Rolling Stones), e discursivo (o jargão empregado pelos moradores da "Alameda do Sol" e pelos agentes do Estado). Não só o espaço geográfico (a rua) e topográfico (o muro e suas instalações) é miniaturizado, mas também o mapa social se apresenta em miniatura, com um número limitado de personagens que estabelecem entre si quatro âmbitos de relação: a família, o amor, a amizade e o Estado (este último, por seu caráter totalitário, abarcando os demais. Anti-miméticos, filme e romance não se propõem enquanto "espelho plano" em sua relação com a "realidade histórica", mas sim como "espelho deformante", pois "deformam" o discurso histórico para produzir riso e, com isso, possibilitam a reconciliação com o passado daquele que recorda.

\section{A4}

\section{A B STRACT}

The objective of this article is to discuss some theoretical aspects about the space in the contemporary literature. On analyzing the novel Am Kürzeren Ende der Sonnenallee (1999), by the German writer Thomas Brussig, this paper argues that the author constructs the fictional space like a miniature by reduction of a small street in the former East Berlin as center of the actions.

\section{KEYWORDS}

Fictional space. Street novel. Am Kürzeren Ende der Sonnenallee.

\section{REFERÊNCIAS}

BRUSSIG, Thomas. Am Kürzeren Ende der Sonnenallee. 4. ed. Berlin: Verlag Volk \& Welt, 1999.

BRUSSIG, Thomas. Der Brechreiz ist ein aktueller. Tagesspiegel, 31 ago. 2003. Disponível em: < http://www.thomasbrussig.de/publizistik/ostalgie.htm>. Acesso em: 13 nov. 2006. BRUSSIG, Thomas; HAUBMANN, Leander. Sonnenallee. 1999. Entrevista concedida a Sandra Maischberger. Disponível em: < http://www.thomasbrussig.de/interviews/sonnenallee.htm>. Acesso em: 13 nov. 2006.

BRUSSIG, Thomas. Herr Brussig, was halten Sie von Nostalgie? Berliner Zeitung, 06/07 nov. 1999. Entrevista concedida a Silke Lambeck. Disponível em: < http://www.thomasbrussig.de/ interviews/berliner htm>. Acesso em: 13 nov. 2006.

BRUSSIG, Thomas. Jubelfeiern wird's geben. Der Spiegel, 06 dez. 1999. Entrevista concedida a Volker Hage. Disponível em: < http://www.thomasbrussig.de/interviews/spiegel.htm>. Acesso em: 13 nov. 2006.

BRUSSIG, Thomas. Nachdenken über Thomas B. Tip-Magazin, n. 21, 1999. Entrevista concedida a Volker Gunske e Sven S. Poser. Disponível em: < http://www.thomasbrussig.de/ interviews/tip.htm >. Acesso em: 13 nov. 2006. 
BRUSSIG, Thomas. Thomas Brussig zweite Heldentat. BZ, 28 ago. 1999. Entrevista concedida a Axel Frohn. Disponível em: < http://www.thomasbrussig.de/interviews/bz.htm>. Acesso em: 13 nov. 2006.

COMPAGNON, Antoine. O demônio da teoria: literatura e senso comum. Belo Horizonte: Editora UFMG, 2001.

HAGEN, Nina; Automobil. Du hast den Farbfilm vergessen. Erfuhrt: East German Press., 1974. Long-Play Single, formato 7".

HAGE, Volker. Der Westen küsst anders. Der Spiegel, 6 set. 1999. Disponível em: < http:/ /www.thomasbrussig.de/sonnenallee/spiegel.htm>. Acesso em: 13 nov. 2006.

KENNTEMICH, Wolfgang et al. (Org.). Das war die DDR. Eine Geschichte des anderen Deutschland. Berlin: Rowohlt, 1993.

KÜHL, Christiane. Sex und Substitutionsdrogen. taz, p. 15, 07 out. 1999. Disponível em: < http://www.thomasbrussig.de/filme/sonnen_taz.htm>. Acesso em: 13 nov. 2006.

KÜPPER, Mechthild. Sieben leere Patronen am Ende der Nacht. FAZ - Frankfurter Allgemeine Zeitung, n. 237, p. L4, 12 out. 1999. Disponível em: <http://www.thomasbrussig.de/ sonnenallee/faz.htm>. Acesso em: 13 nov. 2006.

RAVETTI, Graciela. De Moscou a... Marte. In: NAZARIO, Luis (Org.). A cidade imaginária. São Paulo: Perspectiva, 2005. p. 45-67. (Debates, 302)

SANTOS, Luis Alberto Brandão; OLIVEIRA, Silvana Pessôa de. Sujeito, tempo e espaço ficcionais: introdução à teoria da literatura. São Paulo: Martins Fontes, 2001.

SANTOS, Luis Alberto Brandão. Paul Auster topógrafo: o espaço urbano contemporâneo. Revista de Estudos de Literatura, Belo Horizonte, v. 5, p. 107-122, out. 1997.

SANTOS, Luis Alberto Brandão. Um cachorro corre na cidade vazia. In: MACIEL, Maria Esther; ÁVILA, Myriam; OLIVEIRA, Paulo Motta (Org.). América em movimento: ensaios sobre literatura latino-americana do século XX. Rio de Janeiro: Sette Letras, 1999. p. 147-164.

SCHULDT, Thomas. Zoni macht Winkewinke. Zwischen Ostalgie und Ironie, Pathos und Pointen: Irrungen und Wirrungen der Heranwachsenden im Arbeiter- und Bauernstaat. Rheinischer Merkur, 24 set. 1999. Disponível em: <http:/www.thomasbrussig.de/ sonnenallee/rm.htm >. Acesso em: 13 nov. 2006.

SONNENALLEE. Direção: Leander Haußmann. Alemanha: Boje Buck Produktion, 1999. 1 videodisco (90 min.), son., color. 